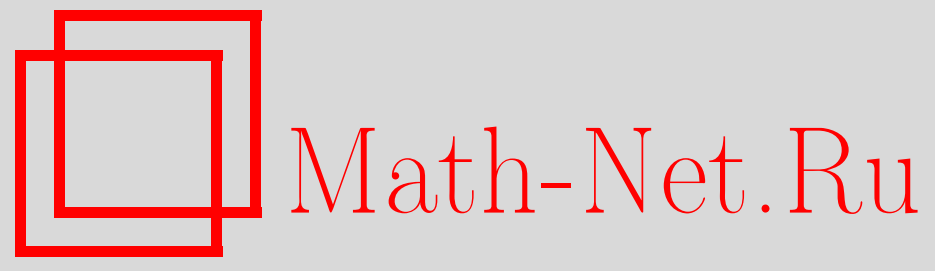

E. Yu. Prosviryakov, Невинтовые точные решения уравнений Эйлера для закрученных осесимметричных течений жидкости, Вестн. Сам. гос. техн. ун-та. Сер. Физ.-мат. науки, 2019, номер 4, 764770

DOI: https://doi.org/10.14498/vsgtu1715

Использование Общероссийского математического портала MathNet.Ru подразумевает, что вы прочитали и согласны с пользовательским соглашением

http://www.mathnet.ru/rus/agreement

Параметры загрузки:

IP: 54.80 .73 .141

26 апреля 2023 г., 12:13:12

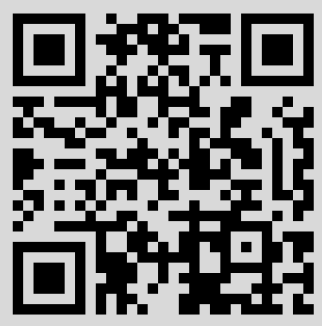




\title{
Non-helical exact solutions to the Euler equations for swirling axisymmetric fluid flows
}

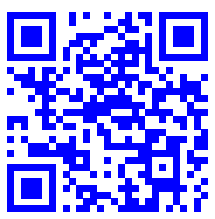

\author{
E. Yu. Prosviryakov ${ }^{1,2}$ \\ 1 Institute of Engineering Science, Urals Branch, Russian Academy of Sciences, \\ 34, Komsomolskaya st., Ekaterinburg, 620049, Russian Federation. \\ 2 Ural Federal University named after the First President of Russia B. N. Yeltsin, \\ 19, Mira st., Ekaterinburg, 620002, Russian Federation.
}

\begin{abstract}
Swirling axisymmetric stationary flows of an ideal incompressible fluid are considered within the framework of the Euler equations. A number of new exact solutions to the Euler equations are presented, where, as distinct from the known Gromeka-Beltrami solutions, vorticity is noncollinear with velocity. One of the obtained solutions corresponds to the flow inside a closed volume, with the nonpermeability condition fulfilled at its boundary, the vector lines of vorticity being coiled on revolution surfaces homeomorphic to a torus.
\end{abstract}

Keywords: Euler equations, ideal incompressible fluid, swirling axisymmetric flows, exact solutions.

Received: $23^{\text {rd }}$ June, 2019 / Revised: $17^{\text {th }}$ August, 2019 Accepted: $16^{\text {th }}$ September, $2019 /$ First online: $6^{\text {th }}$ December, 2019

Introduction. Due to the nonlinearity of isothermal fluid motion equations any patterns, that can be discovered when analytically studying velocity and pressure fields are of interest. These regularities are, e.g., streamline shape [1-3] and vortex line shape [4] properties. In was reported in [4] that "in the stationary axisymmetric flow of a viscous incompressible fluid, the existence of vortex lines lying on a revolution surface homeomorphic to a torus is impossible". In other words, it was demonstrated that the vector lines of the vorticity projection on the meridional plane are nonclosed lines or points. That study offered an example of the stationary axisymmetric flow of an ideal incompressible fluid, where the above-mentioned vector lines either are closed (if they consist of more than one

\section{Short Communication}

ㅇ (ㅇ) The content is published under the terms of the Creative Commons Attribution 4.0 International License (http://creativecommons.org/licenses/by/4.0/)

Please cite this article in press as:

Prosviryakov E. Yu. Non-helical exact solutions to the Euler equations for swirling axisymmetric fluid flows, Vestn. Samar. Gos. Tekhn. Univ., Ser. Fiz.-Mat. Nauki [J. Samara State Tech. Univ., Ser. Phys. Math. Sci.], 2019, vol. 23, no. 4, pp. 764-770. doi: 10.14498/vsgtu1715.

\section{Author's Details:}

Evgeniy Yu. Prosviryakov (1) https://orcid.org/0000-0002-2349-7801

Dr. Phys. \& Math. Sci.; Head of Sector; Sect. of Nonlinear Vortex Hydrodynamics ${ }^{1}$; Professor; Dept. of Theoretical Mechanics ${ }^{2}$; e-mail: evgen_pros@mail.ru 
point), or consist of one isolated point. To put it differently, that was an example of a flow in which the vortex lines lie on a revolution surface homeomorphic to a torus and they are not lathe objects (except one isolated streamline). Hereinafter, lathe objects are a figure of rotation around the axis of symmetry of the flow. That example was one of the Gromeka-Beltrami helical (vorticity is collinear with velocity) solutions $[5,6]$. Here a question arises, whether there exist nonhelical flows of an ideal fluid in with the vortex lines lying on a revolution surface homeomorphic to a torus, which are not lathe objects at that. In this paper we attempt to obtain an example of such a flow.

Among non-helical axisymmetric flows, examples of exact solutions can be easily obtain in the assumption that the radial velocity component is zero, all the parameters being dependent only on the distance to the symmetry axis (the subclass of cylindrical flows). However, in such flows the radial vorticity component is zero, and the vortex lines cannot lie on a revolution surface homeomorphic to a torus. Nonswirling axisymmetric flows are also unsuitable for an example, since in them the projection of the vector lines onto a meridional half-plane are points. We could attempt to seek a solution under other assumptions, simplifying the Euler equations. However, as was reported in [6, 7], simplifying assumptions may lead to equations for which vortex solutions are impossible. To avoid this situation, we decided to search for a suitable example of the stationary axisymmetric solution in in the most general form (without simplifying assumptions). To obtain a new solution, we used Meissel's equation (known as Meissel's formula in the world literature) [8]. This equation is discussed in what follows. Any solution to this equation yields a radial-axial stream function of some solution to the Euler equations. Two arbitrary functions are involved in Meissel's equation, which depend only on the stream function. A special selection of these functions enables us to find solutions to Meissel's equation and thus to find examples of exact solutions. The Gromeka-Beltrami helical solutions correspond to one function selection of the kind. Another one is mathed by the Batchelor solution [9] obtained under an additional simplifying assumption; namely, Batchelor sought a solution among functions independent of the axial coordinate. In this study we consider some other versions of the above-mentioned functions, which, after an appropriate argument substitution, allow Meissel's equation to be solved by the variable separation method. This results in new non-helical and non-cylindrical solutions, this being of interest in itself. One of the solutions offers an example in which the vortex lines lie on revolution surfaces homeomorphic to a torus.

1. Motion equations. We consider the axisymmetric stationary flow of an ideal incompressible fluid. We use the following dimensionless variables: velocity, $\mathbf{V}$; vorticity, $\boldsymbol{\Omega}=\operatorname{rot} \mathbf{V}$; pressure related to density, $p$; the potential of volume forces $\Pi$. Fluid motion is described by the Euler equations, which can be represented in the Gromeka-Lamb form $[9,10]$ as

$$
\begin{gathered}
\mathbf{\Omega} \times \mathbf{V}=-\nabla\left[p+\frac{\mathbf{V}^{\mathbf{2}}}{2}+\Pi\right], \\
\operatorname{div} \mathbf{V}=\mathbf{0} .
\end{gathered}
$$

We introduce a cylindrical coordinate system $r, \varphi, z$ with the origin at point $O$ so that the $O z$ axis coincides with the flow symmetry axis. The axisymmetric 
flow parameters are independent of the circumferential coordinate $\varphi$. Assume that $\mathbf{e}_{r}, \mathbf{e}_{\varphi}, \mathbf{e}_{z}$ is the right-hand system of unit vectors in the radial, circumferential and axial directions, respectively. The swirling flow velocity vector has the form $\mathbf{V}=V_{r} \mathbf{e}_{r}+V_{\varphi} \mathbf{e}_{\varphi}+V_{z} \mathbf{e}_{z}$ and the functions $V_{r}, V_{\varphi}, V_{z}$ and $p$ depend only on $r$ and $z$.

2. Meissel's equation. The theorem stating that all possible streamline functions for stationary axisymmetric flows obey some partial derivative equation is referred to as Meissel's theorem, the equation being termed Meissel's equation (formula). The proof of the theorem can be found in the original study [7] and in the textbook [8], where the name of Meissel is not mentioned. Let us now formulate this theorem. In cylindrical coordinates, in view of the fact that the flow parameters are independent of the circumferential coordinate $\varphi$, the continuity equation (2) is written as

$$
\frac{1}{r} \frac{\partial}{\partial r}\left(r V_{r}\right)+\frac{\partial}{\partial z} V_{z}=0
$$

It follows that there exists a streamline function $\psi=\psi(r, z)$ such that

$$
V_{r}=\frac{1}{r} \frac{\partial}{\partial z} \psi, \quad V_{z}=-\frac{1}{r} \frac{\partial}{\partial r} \psi
$$

We denote

$$
g=r V_{\varphi}
$$

Meissel's theorem implies that, for regions without open zones with zero radialaxial velocity, there can exist such, and only such, axisymmetric solutions to the Euler equations in which Meissel's equation is fulfilled,

$$
\frac{1}{r} \frac{\partial^{2}}{\partial z^{2}} \psi+\frac{\partial}{\partial r}\left(\frac{1}{r} \frac{\partial}{\partial r} \psi\right)+\frac{1}{r} g g^{\prime}=r f,
$$

where $g=g(\psi)$ and $f=f(\psi)$ are one-variable functions.

If $\psi=\psi(r, z)$ is a solution to Eq. (5) for some functions $g=g(\psi)$ and $f=f(\psi)$, then, for an arbitrary axisymmetric potential $\Pi=\Pi(r, z)$, the solution to Eqs. (1), (2) will be the functions $V_{r}, V_{\varphi}, V_{z}$ determined by the equalities (3), (4) and the pressure

$$
p=p_{0}+F(\psi)-0.5\left(V_{r}^{2}+V_{\varphi}^{2}+V_{z}^{2}\right)-\Pi
$$

where $F$ is the primitive function $f$ (i.e. $f=F^{\prime}$ ), $p_{0}$ is any constant ensuring that Eq. (6) will be positive in the flow region under study.

The solutions of Meissel's equations correspond to nonswirling flows $\left(V_{\varphi}=0\right)$ when $g=0$ and to helical flows when $f=0$, and they will be omitted here. In non-helical flows $(f \neq 0)$, both the convective derivative of velocity and the vector product vorticity and velocity are not identically equal to zero, and the Bernoulli function has different values for different streamlines. In what follows we give examples of such exact solutions. 
3. Three solution families. The equation

$$
\frac{\partial}{\partial r}\left(\frac{1}{r} \frac{\partial}{\partial r} \psi\right)+\frac{\partial}{\partial z}\left(\frac{1}{r} \frac{\partial}{\partial z} \psi\right)+\eta^{2} \frac{\psi}{r}=-r \alpha^{2} \psi
$$

where $\alpha, \eta$ are any constants, is a (5)-type equation. For this equation, $F(\psi)=$ $-0.5 \alpha^{2} \psi^{2}$, and one of the solutions is the function $\psi=-\sin \left(\alpha r^{2} / 2\right) \cdot \cos (\eta z)$. In the partial case $\alpha=\eta=1$, the following exact solution is obtained:

$$
\begin{gathered}
V_{r}=\frac{1}{r} \sin \left(r^{2} / 2\right) \cdot \sin (z), \\
V_{\varphi}=-\frac{1}{r} \sin \left(r^{2} / 2\right) \cdot \cos (z), \\
V_{z}=\cos \left(r^{2} / 2\right) \cdot \cos (z), \\
p=p_{0}-0.5 \sin ^{2}\left(r^{2} / 2\right) \cdot \cos ^{2}(z)-0.5\left(V_{r}^{2}+V_{\varphi}^{2}+V_{z}^{2}\right)-\Pi .
\end{gathered}
$$

The radial-axial projections of the streamlines of this cellular flow in the rectangle $\{r ; z\}=[0 ; 2 \pi] \times[0 ; \sqrt{6 \pi}]$ are shown in Fig. 1 . The arrows indicate the direction of the radial-axial velocity.

Figures 2 and 3 show the streamlines of radial-circumferential velocity for three planes perpendicular to the $O z$ axis.

The radial and circumferential velocities tend to zero as the symmetry axis is approached; this enables this solution to be considered in the region containing the symmetry axis. This solution describes the flow in cylindrical barrels (the axis of the cylindrical surface coincides with the $O z$ axis) with radii of $\sqrt{2 \pi}$, $\sqrt{4 \pi}$ and $\sqrt{6 \pi}$, whose bottom and cover have the coordinates $\pi / 2$ and $\pi / 2+m \pi$, $m=1,2,3, \ldots$, along the $O z$ axis. Indeed, it follows from the above expressions for velocity that the impermeability condition is met on the cylindrical walls, on the bottom, and on the cover.

The radial-axial vorticity component

$$
\Omega_{r z}=\frac{1}{r}\left\{\frac{\partial}{\partial z}\left(r V_{\varphi}\right) \mathbf{e}_{r}+\frac{\partial}{\partial r}\left(r V_{\varphi}\right) \mathbf{e}_{z}\right\}
$$

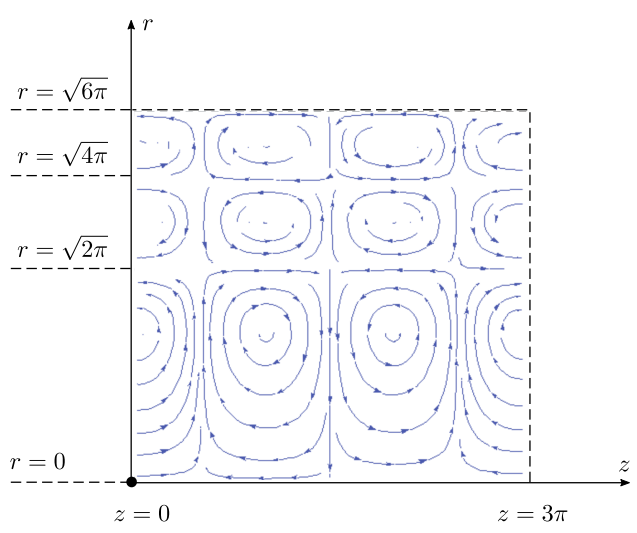

Figure 1. The radial-axial projections of the streamlines of the cellular flow

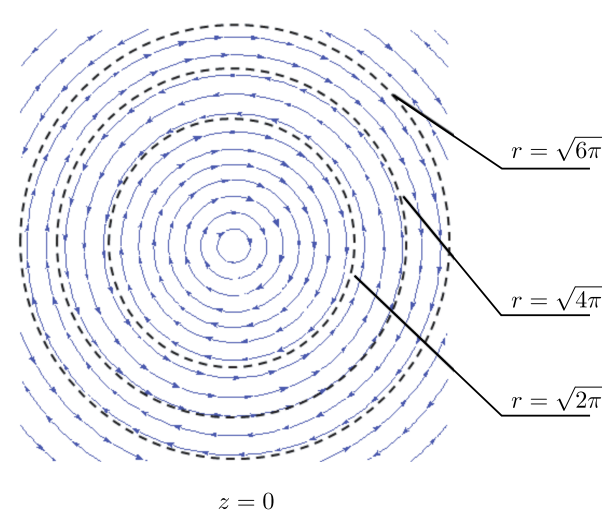

Figure 2. The streamlines of radial-circumferential velocity for $z=0$ 

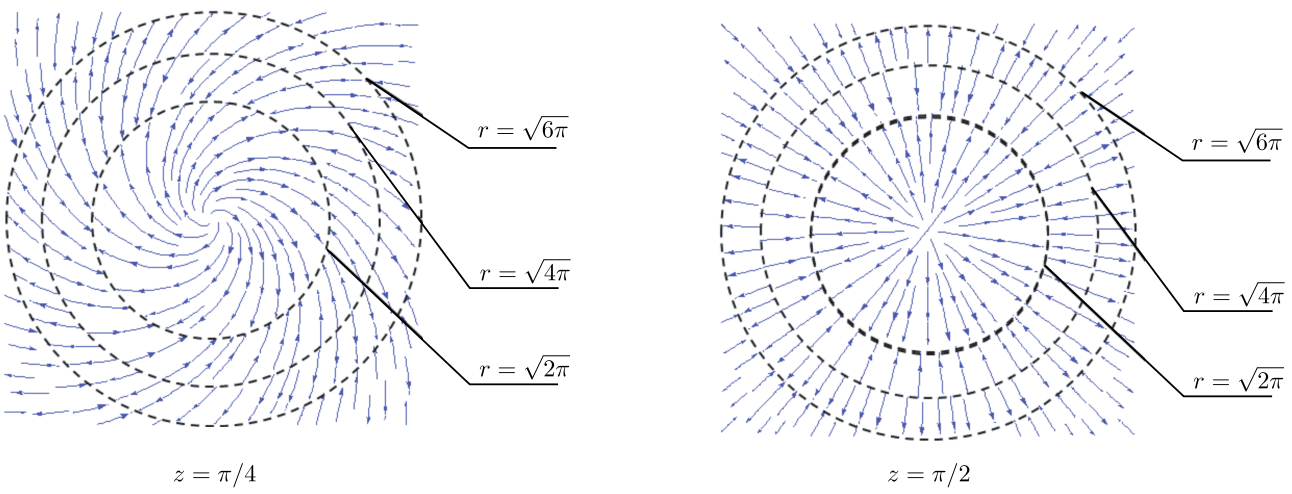

Figure 3. The streamlines of radial-circumferential velocity for $z=\pi / 4$ and $z=\pi / 2$

lies on the lines of the form $r V_{\varphi}=$ const. It follows from Eq. (8) that, for the found solution, they are lines of the form $\sin \left(r^{2} / 2\right) \cdot \cos (z)=$ const. It can be easily believed that these lines are closed and that they once enclose the points with the coordinates $r_{m}=\sqrt{2 m \pi+\pi}, z_{j}=j \pi, m=0,1,2,3, \ldots, j=0, \pm 1, \pm 2, \pm 3, \ldots$. These points are isolated. Consequently, except the isolated vortex lines going through these points, the vortex lines (8) are not lathe objects, and they lie on revolution surfaces homeomorphic to a torus (the search for such a solution is the main aim of this study).

Another solution family is obtained if we consider the following (5)-type equation:

$$
\frac{\partial}{\partial r}\left(\frac{1}{r} \frac{\partial}{\partial r} \psi\right)+\frac{\partial}{\partial z}\left(\frac{1}{r} \frac{\partial}{\partial z} \psi\right)+\eta^{2} \frac{\psi}{r}=r \alpha^{2} \psi
$$

where $\alpha, \eta$ are any constants. For this equation, $F(\psi)=\alpha^{2} \psi^{2} / 2$, the functions $\psi=\exp \left(\alpha r^{2} / 2\right) \cdot \sin (\eta z)$ and $\psi=\exp \left(-\alpha r^{2} / 2\right) \cdot \sin (\eta z)$ being the solutions. These solutions are unsuitable for studying flows in channels containing the $O z$ axis. The fact is that the radial velocities $V_{r}=\eta \frac{1}{r} \exp \left( \pm \alpha r^{2} / 2\right) \cdot \cos (\eta z)$ corresponding to these solutions have a peculiarity on the $O z$ axis. However, due to the linearity of Eq. (7), the linear combination of these solutions $\psi=\sinh \left(\alpha r^{2} / 2\right) \cdot \sin (\eta z)$ is also a solution to Eq. (7). The corresponding solution of the Euler equations has the form

$$
\begin{gathered}
V_{r}=\eta \frac{1}{r} \sinh \left(\alpha r^{2} / 2\right) \cdot \cos (\eta z), \\
V_{\varphi}=\eta \frac{1}{r} \sinh \left(\alpha r^{2} / 2\right) \cdot \sin (\eta z), \\
V_{z}=-\alpha \cosh \left(\alpha r^{2} / 2\right) \cdot \sin (\eta z), \\
p=p_{0}+0.5 \alpha^{2} \sinh ^{2}\left(\alpha r^{2} / 2\right) \cdot \sin ^{2}(\eta z)-0.5\left(V_{r}^{2}+V_{\varphi}^{2}+V_{z}^{2}\right)-\Pi .
\end{gathered}
$$

In this solution, all the parameters admit the continuation on the $O z$ axis; herewith, the radial and circumferential velocities tend to zero as the symmetry axis is approached, and this allows us to formulate a boundary problem with a known exact solution of the flow in an axisymmetric channel containing the symmetry axis. It seems excessive to illustrate this flow. The third solution family 
is represented by solutions of the following (5)-type equation:

$$
\frac{\partial}{\partial r}\left(\frac{1}{r} \frac{\partial}{\partial r} \psi\right)+\frac{\partial}{\partial z}\left(\frac{1}{r} \frac{\partial}{\partial z} \psi\right)+\lambda^{2} \frac{\psi}{r}=r \lambda^{2},
$$

where $\lambda$ is any constant. For this equation, $F(\psi)=\lambda^{2} \psi$, and the solutions $\psi=$ $\psi(r, z)$ will be all the known helical solutions with a constant coefficient $\lambda$ relating velocity to vorticity if the function $r^{2}$ is added to them. This corresponds to the addition of constant velocity along the symmetry axis, and new solutions will no longer be helical.

Conclusion. Within the framework of the Euler equations, we have discussed swirling axisymmetric stationary flows of an ideal incompressible fluid in a potential field of external forces. Three new families of exact solutions have been obtained. As distinct from Gromeka's solution, vorticity is not parallel to fluid velocity in these families, and in contrast to cylindrical flows, the radial velocity component is not identically equal to zero. The solution (8) is a solution to the problem of motion inside a barrel (inside a portion of a straight cylinder), with the impermeability condition met on its walls. The vortex lines of this flow, not being lathe objects (except isolated lines), lie on revolution surfaces homeomorphic to a torus.

Competing interests. I have no competing interests.

Author's Responsibilities. I take full responsibility for submitting the final manuscript in print. I approved the final version of the manuscript.

Funding. This work was partially supported by the Complex Program of UB RAS, project no. $18-1-1-5$.

\section{References}

1. Arnold V. I. Sur la topologie des écoulements stationnaires des fluides parfaits, In: Vladimir I. Arnold - Collected Works, vol. 2; A. Givental, et all. Berlin, Heidelberg, Springer, 1965, pp. 15-18. doi : 10.1007/978-3-642-31031-7_3.

2. Kozlov V. V. Notes on steady vortex motions of continuous medium, J. Appl. Math. Mech., 1983, vol. 47, no. 2, pp. 288-289. doi: 10.1016/0021-8928(83)90020-5.

3. Kozlov V. V. General Vortex Theory. Izhevsk, Udmurtia Univ., 1998, 238 pp. (In Russian)

4. Sizykh G. B. Helical vortex lines in axisymmetric viscous incompressible fluid flow, Fluid Dyn., 2019, vol. 54, no. 8, pp. 1038-1042. doi : 10.1134/S0015462818060083.

5. Gromeka I. S. Collected works. Moscow, Acad. Sci. USSR, 1952, 296 pp. (In Russian)

6. Beltrami E. Considerazioni idrodinamiche, Rend. Inst. Lombardo Acad. Sci. Lett., 1889, vol. 22 , pp. $122-131$.

7. Sizykh G. B. Axisymmetric helical flows of viscous fluid, Russian Mathematics, 2019, vol. 63, no. 2, pp. 44-50. doi : 10.3103/S1066369X19020063.

8. Meissel E. Über den Ausfluss des Wassers aus Gefässen in zwei besonderen Fällen nach Eintritt des Beharrungszustandes, Grunert Arch., 1873, vol. 55, pp. 241-252 (In German).

9. Batchelor G. K. An Introduction to Fluid Dynamics. Cambridge, Cambridge Univ. Press, 1999, xvii+615 pp. doi: 10.1017/CB09780511800955.

10. Loitsyanskii L. G. Mechanics of Liquids and Gases. Oxford, Pergamon Press, 1972, xii +802 pp. 
Вестн. Сам. гос. техн. ун-та. Сер. Физ.-мат. науки. 2019. Т. 23, № 4 . С. $764-770$ ISSN: 2310-7081 (online), 1991-8615 (print)

УДК 532.51, 517.958:531.3-324

\title{
Невинтовые точные решения уравнений Эйлера для закрученных осесимметричных течений жидкости
}

\author{
Е. Ю. Просвиряков ${ }^{1,2}$ \\ 1 Институт машиноведения УрО РАН, \\ Россия, 620049, Екатеринбург, ул. Комсомольская, 34. \\ 2 Уральский федеральный университет \\ им. первого Президента России Б. Н. Ельцина, \\ Россия, 620002, Екатеринбург, ул. Мира, 19.
}

\section{Аннотация}

В рамках уравнений Эйлера рассмотрены закрученные осесимметричные стационарные течения идеальной несжимаемой жидкости. Представлено несколько новых точных решений уравнений Эйлера, в которых, в отличие от известных решений Громеки-Бельтрами, завихренность неколлинеарна скорости. Одно из полученных решений соответствует течению внутри замкнутого объема, на границе которого выполнено условие непротекания, а векторные линии завихренности наматываются на гомеоморфные тору поверхности вращения.

Ключевые слова: уравнения Эйлера, идеальная несжимаемая жидкость, закрученные осесимметричные течения, точные решения.

Получение: 23 июня 2019 г. / Исправление: 17 августа 2019 г. / Принятие: 16 сентября 2019 г. / Публикация онлайн: 6 декабря 2019 г.

Конкурирующие интересы. Конкурирующих интересов не имею.

Авторская ответственность. Я несу полную ответственность за предоставление окончательной версии рукописи в печать. Окончательная версия рукописи мною одобрена.

Финансирование. Работа частично поддержана Программой комплексных фундаментальных исследований УрО РАН (проект № 18-1-1-5).

\section{Краткое сообщение}

(2) (ㄱ) Контент публикуется на условиях лицензии Creative Commons Attribution 4.0 International (https://creativecommons.org/licenses/by/4.0/deed.ru)

\section{Образец для цитирования}

Prosviry akov E. Yu. Non-helical exact solutions to the Euler equations for swirling axisymmetric fluid flows, Vestn. Samar. Gos. Tekhn. Univ., Ser. Fiz.-Mat. Nauki [J. Samara State Tech. Univ., Ser. Phys. Math. Sci.], 2019, vol. 23, no. 4, pp. 764-770. doi: 10.14498/vsgtu1715.

\section{Сведения об авторе}

Евгений Юръевич Просвиряков (10) https://orcid.org/0000-0002-2349-7801

доктор физико-математических наук; заведующий сектором; сектор нелинейной вихревой гидродинамики ${ }^{1}$; профессор; кафедра теоретической механики ${ }^{2}$;

e-mail: evgen_pros@mail.ru 